\title{
DETERMINACIÓN DE LA PRODUCTIVIDAD Y COMPETITIVIDAD DE LA PEQUEÑA MINERÍA DEL DISTRITO MINERO DEL NORTE DE BOYACÁ
}

\section{PRODUCTIVITY AND COMPETITIVENESS DETERMINATION OF THE SMALL-SCALE MINING AT THE NORTHERN MINING DISTRICT IN THE STATE OF BOYACÁ}

\author{
Martha Stella Martínez Bernal
}

\section{Resumen}

En los últimos años, la actividad minera en Colombia ha venido creciendo progresivamente, a tal punto que el país es considerado el primer productor de carbón en América Latina y duodécimo en el mundo. En el departamento de Boyacá, concretamente, la minería del carbón generó el año pasado un movimiento económico cercano a los 380.000 millones de pesos. La necesidad de conocer a fondo el nivel de productividad y competitividad de la pequeña minería en el distrito minero del norte de este departamento, motivó la realización de esta investigación. Este documento presenta un estudio efectuado a veinte títulos mineros ubicados en diferentes municipios de este distrito minero, que permitió identificar las debilidades y fortalezas en aspectos de productividad y competitividad de la pequeña minería ubicada en este distrito. Así mismo, plantea una serie de mecanismos y estrategias que permitan, desde el punto de vista empresarial, mejorar las falencias que presenta el sector de la pequeña minería del departamento.

Palabras clave: distrito minero, productividad, competitividad, minería de carbón, titular minero. \begin{abstract}
Recibido: Enero 28 de 2013
Aceptado: Junio 20 de 2013
Abstract

In recent years, mining in Colombia has been growing to such an extent that the country is considered to be the largest producer of coal in Latin America and the 12th in the world. In the Department of Boyaca, specifically, the coal mining production generated an economic movement closed to 380000 million pesos last year The need to know the level of productivity and competitiveness of small-scale mining in the mining district of the north of this department, promotes this investigation. This document contains a study of twenty mining titles located in different municipalities of this mining district, which allowed us to identify he strengths and weaknesses in areas of productivity and competitiveness of small-scale mining of the district. Likewise, it raises a number of mechanisms and strategies to improve, from the business standpoint, the shortcomings presented by the small-scale mining sector.
\end{abstract}

Key words: mining district, productivity, competitiveness, coal mining, mining holder. 


\section{Introducción}

En los últimos años, la actividad minera en Colombia ha venido creciendo progresivamente, a tal punto que el país es considerado el primer productor de carbón en América Latina y duodécimo en el mundo (Plan Nacional de Desarrollo Minero, [PNDM] 2002). Efectivamente, en Colombia la minería ha aumentado su producción total durante los últimos veinte años. La producción total se triplicó (de 31.750 K-Ton en los 90 a 86,750 K-Ton en 2010).

En el desarrollo de la IV Feria Minería Colombia, que se llevó a cabo recientemente en Corferias, la Agencia Nacional de Minería reportó que la pequeña y mediana minería de carbón registró durante el primer semestre de este año un leve crecimiento, del $2 \%$, en su producción al pasar de 3.5 millones de toneladas en igual periodo de 2012, a 3.6 millones de toneladas en el primer semestre de 2013 (Agencia Nacional de Minería, [ANM] 2013). Dicho repunte obedece al comportamiento de algunos departamentos productores, como en el caso de Cundinamarca, cuya producción de carbón aumentó hasta 1.4 millones de toneladas. Igualmente, Boyacá registró un alza de $13 \%$, mientras que Santander subió un 4\%; Estos departamentos representan el $9 \%$ del total de la producción carbonífera del país.

Pese a que en Boyacá la minería del carbón generó el año pasado un movimiento económico cercano a los 380.000 millones de pesos, esta industria continúa manejándose de forma artesanal. En este departamento existen 600 títulos mineros para extracción de carbón y cerca de 3.000 bocaminas, entre legales e ilegales. Precisamente la falta de tecnología en las explotaciones carboníferas y la minería ilegal hacen que la industria del carbón en Boyacá sea un negocio incierto (Portafolio, 2011). De acuerdo con la Unidad de Planeación Minero Energética, UPME (2007), Colombia debe adoptar modelos, estrategias y escenarios dentro de sus políticas de competitividad del sector minero, que conlleven al mejoramiento de la productividad y competitividad de la minería, ya que la pequeña minería deja ver las necesidades de crecimiento y apoyo que requiere por parte del Gobierno nacional.

La necesidad de conocer a fondo el nivel de productividad y competitividad de la pequeña minería en el distrito minero del norte de Boyacá, motivó esta investigación para identificar las debilidades y fortalezas de este sector, teniendo en cuenta que las políticas del Gobierno están enfocadas al desarrollo sostenible y competitivo de la minería en Colombia. Éste desarrollo sostenible incorpora una visión más amplia del desarrollo, pues busca conciliar la producción con el uso sustentable del patrimonio natural y la protección del medio ambiente.

Éste documento expone los resultados de un estudio llevado a cabo sobre veinte títulos mineros, ubicados en el distrito minero del norte de Boyacá, con el cual se reconocieron las principales causas de los bajos niveles de productividad y competitividad de este sector. También se plantean una serie de estrategias, como mecanismos de control y mejoramiento para la pequeña y mediana minería del departamento de Boyacá.

\section{Marco teórico y metodología}

\subsection{Marco teórico}

Antes de analizar la productividad y competitividad de la pequeña minería en el distrito minero del norte de Boyacá, es importante definir algunos términos como distrito minero, productividad y competitividad, entre otros.

\section{Distrito minero}

El Ministerio de Minas y Energía a través de la UPME (2005), ha manifestado la importancia de precisar el concepto de distrito minero; por eso ha aclarado que la definición contenida en el Glosario Minero (2002), vigente en el país, no es fácilmente 
aplicable. Ésta definición, que fue tomada textualmente del US Bureau of Mines (1996), reza como sigue: Porción o área de terreno de un país, generalmente designada por un nombre, cuyos límites han sido descritos y dentro de la cual existen minerales que son extraídos siguiendo las reglas y regulaciones establecidas por los mineros locales.

En la definición de distrito minero no existe límite de extensión territorial y sus linderos se pueden cambiar siempre y cuando, no se interfieran otros derechos. En Colombia, por el contrario, al ser de propiedad del Estado todos los minerales del suelo y del subsuelo, las reglas y resoluciones no son establecidas por los mineros sino por el mismo Estado.

En la antigua empresa Mineralco se definió el distrito minero como: aquella región cuya actividad económica principal es la explotación de uno o más minerales, organizada en unidades empresariales con utilización de mano de obra local, que cumpla con el desarrollo racional de sus explotaciones con parámetros de viabilidad técnica, económica, social y ambiental, para el logro de su desarrollo integral, que armonice las actividades económicas, los usos del suelo y el subsuelo con las aspiraciones comunitarias, la cultura y el progreso regional y nacional (Mineralco, 1999). Sin embargo, esta definición nunca se adoptó formalmente, seguramente porque descartaba un buen número de zonas del país donde la minería es una más de sus actividades económicas, pero que cuentan con un significativo potencial minero y originan una importante producción mineral.

Por lo anterior, el Ministerio de Minas y Energía consideró necesario definir unos criterios que sirvieran de base para la caracterización, identificación y selección de las zonas del país que podrían ser catalogadas como distritos mineros. Los criterios tenidos en cuenta fueron: i) el tipo de material mineral y el volumen de producción; ii) el grado de concentración minera frente a zonas relativamente homogéneas y uniformes, y iii) la tradición minera de las comunidades locales y regionales (UPME, 2005).

En tal sentido, se identificaron los minerales más representativos de la producción minera nacional en relación con los volúmenes de producción que pueden considerarse significativos desde el punto de vista del mercado de cada uno de ellos. Después se localizaron las áreas productivas y se identificaron las zonas geográficas que cumplían con el criterio de concentración minera.

En general afirma la UPME que un distrito industrial o minero se puede definir como: un sistema productivo localizado donde se ubica un buen número de productores dedicados a manufacturar o explotar, en distintas fases, un producto homogéneo o un mineral o grupo de minerales. La actividad de estas empresas pertenece a un mismo ciclo de producción con diferentes responsabilidades estratégicas (UPME, 2005, p. 11).

\section{Competitividad y productividad}

El concepto de competitividad, aplicado a escala nacional, surgió a mediados de la década del ochenta en los Estados Unidos como una cuestión centrada en el vínculo entre el avance económico de los países y su participación en los mercados internacionales. La definición más conocida, señala que competitividad es: la capacidad de un país para sostener y expandir su participación en los mercados internacionales y elevar simultáneamente el nivel de vida de la población (Commission on Industrial Competitiveness, 1985).

Otros autores adaptaron el concepto de competitividad a los sectores y actividades productivas, y a partir de ellos a regiones geográficas. Para medir las capacidades competitivas de las regiones de un país se han diseñado diversas metodologías que cuentan con un buen número de casos aplicados. La base 
común de estas mediciones es la técnica denominada "benchmarking", que consiste en la evaluación comparativa de desempeño económico de varias regiones, mediante la utilización de determinados criterios: estructura sectorial, grado de internacionalización, calidad de gobierno, gerencia privada, dotación de infraestructura, eficiencia del sector financiero, ciencia y tecnología y el capital humano.

Para Mintzberg (1997), la competitividad es la capacidad de una empresa u organización de cualquier tipo para desarrollar y mantener unas ventajas comparativas que le permiten disfrutar, sostener y mejorar una posición destacada en el entorno socioeconómico en que actúan. Se entiende por ventaja comparativa aquella habilidad, recurso, conocimiento y atributos de que dispone una empresa. Para este mismo autor, la productividad se define como la"medida en que una nación, bajo condiciones de mercado libre y leal es capaz de producir bienes y servicios que puedan superar con éxito la prueba de los mercados internacionales, manteniendo y aun aumentando al mismo tiempo la renta real de sus ciudadanos"(Mintzberg, 1997).

\section{Clusters}

El concepto de "clusters", que desde hace algunos años ha tomado mucha fuerza, según Michael Porter (1998) citado por (Moncayo, 2003), es el siguiente: concentraciones geográficas de firmas e instituciones interconectadas en un determinado sector, ligadas entre sí, comprenden una gama de industrias y otras actividades importantes para la competitividad. Cuentan con proveedores de insumos especializados como componentes, maquinaria, servicios e infraestructura especializada. Frecuentemente se extienden hacia adelante para incluir los canales de distribución a los clientes y horizontalmente hacia los fabricantes de productos complementarios y firmas en sectores relacionados por tecnología, habilidades o insumos comunes. Igualmente muchos incluyen instituciones gubernamentales y de otra índole como universidades, agencias de normalización, centros de investigación, asociaciones gremiales y centros de formación vocacional.

Se presenta el concepto de cluster porque sobre el tema de los recursos naturales han surgido nuevos enfoques que están revalorizando el concepto de que estos factores bien aprovechados pueden contribuir al desarrollo, tal como ha ocurrido en los países nórdicos, Canadá, Australia y Nueva Zelanda. Una de las claves está en industrializar y procesar los recursos naturales a través de la conformación de clusters que integren, en el caso de la explotación de recursos mineros, actividades de beneficio y transformación de minerales con las de soporte (proveedores de insumos, servicios de ingeniería y equipos, centros de capacitación, etc.). En este sentido, un estudio del Banco Mundial (2002) señala que si un país rico en recursos naturales adopta en forma eficiente las tecnologías apropiadas, puede crecer de manera similar a los que basan su crecimiento en el sector industrial.

\section{Características de la pequeña minería}

Según la CEPAL, la característica fundamental de lo que se ha denominado pequeña minería, radica en la imposibilidad de definirla de acuerdo con parámetros de medición universales. Una característica que sí permite diferenciarla es su distribución geográfica, legislación nacional y ejecución de política minera (Chaparro, 2000). Sobre este intento de encontrar características que identifiquen este segmento de la producción minera, son numerosos los esfuerzos por cuantificar la condición más reconocida de la actividad minera a pequeña escala como es el empleo, el recurso humano dedicado a ella.

En este sentido, el Comité de Recursos Naturales de las Naciones Unidas, en 1996 manifestó con relación a la pequeña minería, que ésta ocupa importantes volúmenes de mano de obra en todo el mundo; el Consejo Económico y Social de las 
Naciones Unidas estima que en el mundo puede haber cerca de seis millones de personas ocupadas de manera directa con esta actividad, de ellas depende un número que excede los seis millones; es decir, más del $20 \%$ de quienes trabajan con el sector en su conjunto. Si se supone que en promedio hay otros cuatro familiares por trabajador, una hipótesis moderada, entonces más de 30 millones de personas dependen directamente de la minería artesanal y en pequeña escala para su subsistencia económica. Si se suponen otros nueve familiares por trabajador como una estimación por exceso, el total se eleva a más de 60 millones de personas (Organización de las Naciones Unidas, [ONU] 1996).

Para el caso de Colombia, Benavides y Rosso (2010) caracterizan esta actividad así: i) Artesanal: con una producción promedio de 50 a 200 toneladas al mes, provee un máximo de 5 a 10 empleados, en general no es legal y lleva a cabo un proceso de extracción rudimentaria (pico y pala); ii) Pequeña: un minero que tiene de 1 a 3 minas con una producción de 1000 a 1500 toneladas aproximadamente, tiene entre 10 y 25 empleados (95\% son obreros rasos), son legales o están en proceso de legalización, han invertido en infraestructura (tiene un compresor, sistema de ventilación, etc.), ofertas de casino y campo de los mineros extranjeros.

\section{La minería en Boyacá}

Las áreas de reserva de carbón de Boyacá van desde el municipio de Jericó, al norte, hasta la frontera con el departamento de Cundinamarca, la zona minera principal se encuentra entre los municipios de Sogamoso y Jericó, con carbones bituminosos (Benavides \& Rosso, 2012). En Boyacá, el carbón metalúrgico representa alrededor de $58 \%$ de la producción total de carbón, mientras que el carbón térmico es la complementaria del $42 \%$ sobre el total. Según la Federación Nacional de Productores de Carbón (Fenalcarbón), las reservas de carbón en Boyacá, Cundinamarca y Santander ascienden a aproximadamente 2.000 millones de toneladas. De estas reservas, cerca de 1.000 millones serían de carbón metalúrgico, bastante apetecido en la industria siderúrgica porque convertido en coque es materia prima esencial en la fabricación de acero (Portafolio, 2011).

La extracción de este mineral se caracteriza por ser, entre el $70 \%$ u $80 \%$, una actividad ilegal. En general, la minería ilegal está presente en el $44 \%$ del total de municipios en el país y representa cerca del $30 \%$ de las exportaciones mineras totales (Ardila, 2010). Según Fedesarrollo (2011), la actividad minera está reemplazando a las actividades primarias de la región: la agricultura y la ganadería. Se estima que el $48 \%$ de la minería es artesanal, el $38 \%$ a pequeña escala, y sólo el $14 \%$ es de media a gran escala. Esto implica un escaso desarrollo de la tecnología y una alta dependencia de mano de obra.

Sobre el financiamiento, en el Congreso Nacional de Minería efectuado en marzo de 2012, en Paipa, Boyacá, sobre acceso a recursos del sector financiero, se concluyó que es precario, sobre todo para los mineros de menor tamaño. Además, se accede cuando las entidades logran conocimiento de sus clientes. Este acercamiento se logra fundamentalmente a nivel local, donde los gerentes de las oficinas tienen la posibilidad de obtener mayor información de sus clientes. Acceden a créditos personales de bajos montos. Toman contratos de leasing, fundamentalmente para compra de volquetas. No se evidencia, sin embargo, que las inversiones en la mina ni el capital de trabajo, provengan de estas alternativas.

La CEPAL señala que las dificultades financieras para la obtención de recursos frescos es otro de los atributos típicos de la actividad extractiva a baja escala. Esto se origina en la falta de garantías reales para avalar los créditos, en la ausencia de un derecho minero y baja certidumbre sobre el potencial del yacimiento, entre otras razones (Chaparro, 2000). 
El bajo conocimiento del negocio minero, permite que los operadores financieros vean con recelo las solicitudes de crédito presentadas por los pequeños mineros y las cooperativas. A su vez, la mayor parte de los mineros que han pensado en solicitar un crédito desconocen los procedimientos, construyéndose de esta manera un círculo poco virtuoso que el sector financiero no está interesado en romper, pues tiene suficientes clientes en otros sectores económicos. Esta situación conlleva a que el minero acuda al crédito extrabancario o agote rápidamente su liquidez, con lo que ello implica. De esta forma se explica el alejamiento del pequeño minero y las cooperativas mineras de las fuentes de recursos frescos. La situación de desvinculación del sector minero de las fuentes de financiamiento es de tal magnitud, que una encuesta realizada por la UPME con el sector financiero colombiano, reveló que más del sesenta por ciento (70\%) de las solicitudes de crédito son rechazadas por estar mal solicitadas.

En cuanto a la ilegalidad y derechos de propiedad, en el mencionado Congreso Nacional de Minería se explicó que las asimetrías entre los productores y consumidores, conlleva problemas relacionados con los derechos de propiedad. A pesar de que el minero es el dueño de los recursos, la estructura de negociación impone restricciones a los derechos residuales. Cuando el comprador provee recursos financieros al productor, o presta servicios como el transporte del mineral, tiene un poder en la relación contractual que lo convierte en demandante residual. Esto causa una caída en los beneficios privados para el productor Hart y Holmstrom (2010), citado por (Benavides y Rosso, 2012).

Sobre el problema de la ilegalidad, Jaime Chiquillo, gerente operativo de la carbonera Sanoha, dice que la minería ilegal es una competencia desleal que amenaza la industria. La minería ilegal no paga seguridad social, no invierte en tecnología, contamina el ambiente y no cumple con las mínimas normas de seguridad.
Aunque en Boyacá existen algunas empresas mineras grandes, un gran porcentaje son microempresas familiares que extraen el carbón a pico y pala y utilizan viejos motores de carros para mover los malacates que sacan los coches con el mineral del fondo de los socavones (Portafolio, 2011).

En cuanto a los compradores, en el Congreso Nacional de Minería se dijo que existen tres clases de compradores: Intermediadores: 90 días, ofrecen financiación, definen precios, Comercializadores: permanentes con instalaciones y servicios adicionales, Temporales: oportunistas, pagan en efectivo.

La dotación de infraestructura de un país constituye un factor importante de su competitividad. En la industria minera, en particular, la infraestructura está relacionada en forma directa con las distintas actividades y costos del proceso minero, desde el inicio de la prospección-exploración, hasta las etapas de desarrollo, producción y comercialización. Consecuentemente, la disponibilidad, especificaciones técnicas, tarifas de los diferentes medios de transporte, constituyen elemento fundamental en la estructura de costos de un proyecto minero. Esta variable es particularmente sensible en la etapa de producción, en la cual el producto minero o derivados destinados a los mercados internacionales deben ser colocados en puerto. Sin embargo un alto porcentaje de los proyectos mineros presenta un riesgo elevado y son casi marginales en cuanto a su rentabilidad, aspectos que dificultan su puesta en operación, especialmente si tienen que asumir costos de infraestructura (UPME, 2005).

\subsection{Metodología y población}

La metodología utilizada para esta investigación fue de tipo inductivo por medio de un análisis ordenado, coherente y lógico del problema por investigar, en este caso, la determinación del grado de productividad y competitividad de la 
pequeña minería en el distrito minero del norte de Boyacá.

Éste distrito minero se halla constituido por 23 municipios, pertenecientes a cuatro provincias: Gutiérrez, La Libertad, Norte y Valderrama; los municipios que lo conforman son: Betéitiva, Boavita, Chiscas, Chita, Covarachía, El Cocuy, El Espino, Güicán, Jericó, La Uvita, Panqueba, Paya, Paz de Río, Pisba, San Mateo, Sativanorte, Sativasur, Soatá, Socotá, Socha, Susacón, Tasco y Tipacoque (Ardila, 2010).

Para la selección de los títulos se tuvo en cuenta el tiempo que llevaban los mineros desarrollando la actividad, las reservas probadas y calculadas de carbón, la producción mensual, la estructura de costos, el número de trabajadores, la estructura orgánica, las fuentes de financiamiento, la planeación de las distintas actividades contempladas en el PTP (plan de trabajo y obras), entre otros aspectos que permiten determinar las fortalezas y debilidades en cuanto al tema de productividad y competitividad de la minería en esta zona del departamento de Boyacá.

La población base del estudio fueron veinte títulos mineros, con una producción mensual menor a 600 toneladas. Los municipios y títulos seleccionados son los siguientes: Tasco (050-93, 943T, BKS-081, DEN-142, FEV-161, FF7-082), Sátivasur (123-92, FG8-091, 141-92, 119-92, 12592, DH9-152), San Mateo (FLN-133,GBN-152), Paz del Río (01-007-96, FG8-153) y Socha (FER-153, FD5-082, CDK-102).

Las técnicas utilizadas para la recolección de información del proyecto fueron la observación y la encuesta; en la primera, se realizaron visitas de campo a los títulos mineros seleccionados, con el fin de identificar las fortalezas y debilidades en los aspectos de productividad y competitividad. En la segunda se diseñó un formulario que permitió establecer el grado de productividad y competitividad de los títulos mineros; esta encuesta tiene preguntas acerca de inversiones, capacidad de producción, costos, gastos, ventas, endeudamiento, capacidad de pago, estructura orgánica (distribución de funciones y reglamento interno de trabajo), entre otras.

\section{Resultados y discusión}

En ésta sección se presentan los resultados de la investigación, organizados en tres apartados, a saber: en el primero se describe el estado actual de las variables que identifican la competitividad y productividad, en el segundo se establecen las fortalezas y debilidades, mientras que en el tercer apartado se enuncian algunas estrategias de mejoramiento para la competitividad y productividad del sector minero del departamento de Boyacá.

\subsection{Productividad y competitividad}

Tiempo en la actividad minera: Los resultados obtenidos indican que los titulares mineros tienen amplia experiencia en el campo de la exploración y explotación minera, el $40 \%$ tiene una antigüedad entre 10 y 15 años, el 30\% lleva más de 15 años en el ejercicio, el $20 \%$ entre 5 y 10 años de experiencia y el $10 \%$ entre 1 y 5 años en la actividad minera.

Reservas de carbón en títulos: El 70\% de los titulares mineros saben que geológicamente poseen reservas de carbón para ser explotadas en los próximos diez años, el 15\% tiene reservas para explotar en tiempo menor a diez años, el 10\% no sabe y el $5 \%$ afirma que las reservas no están probadas.

Planeación financiera: Con respecto a la planeación financiera, los titulares afirmaron que nunca hicieron algún tipo de proyección. El $60 \%$ de los titulares no realizó planeación financiera a corto ni a largo plazo, no tuvo en cuenta que su dinero debía tener una tasa de retorno; el $40 \%$ afirma que sí efectuó planeación sobre inversiones, costos, gastos, utilidad, rentabilidad; el $85 \%$ de la población objeto de estudio, no posee 
las herramientas, maquinarias, equipos y tecnologías adecuadas que le permitan lograr un mayor desempeño en la actividad minera; el 15\% afirma tener infraestructura para desarrollar la extracción del carbón a mayor escala, el $80 \%$ de la población minera no cuenta con una estructura de costos definida, afirma desconocer los costos unitarios de producción de tonelada de carbón, los ingresos, egresos, rentabilidad y utilidad neta; el $20 \%$ afirma tener definida la estructura de costos y la importancia para el buen desempeño de una empresa, aseveran que para poder proyectarse hacia el futuro y permanecer en el mercado es fundamental conocer la parte económica y financiera de su empresa.

Recursos económicos: La principal debilidad de los titulares mineros (45\%), es la falta de recursos propios, para adquirir maquinaria y equipos de trabajo y con ello lograr una mayor producción de carbón; el 30\% afirma que la rentabilidad obtenida por la actividad minera no permite realizar inversiones y mejoras notorias para aumentar la producción, esto debido a las difíciles condiciones actuales del mercado del carbón a nivel nacional, el $25 \%$ dice no tener fácil acceso a fuentes de financiamiento, debido a que la banca nacional les pide muchas garantías para otorgarles un crédito, por el riesgo del precio del carbón en los mercados internacionales. Vale anotar que en este aspecto -- recursos económicos - se observa concordancia con lo expuesto anteriormente en este artículo sobre financiamiento.

Rentabilidad de la actividad minera: El 70\% de los titulares mineros afirma que los ingresos obtenidos sí cubren los costos totales de producción para desarrollar su actividad minera; el $20 \%$ de los entrevistados dice no alcanzar a cubrir los costos operacionales, por la falta de estructura de costos, y el 10\% considera que en algunas ocasiones no obtiene suficientes ingresos operacionales para cubrir los costos de producción, y afirma que ha habido dificultades en el mercado que los ha impactado fuertemente.
Reinversión de utilidades: El 30\% de la población entrevistada asegura que los excedentes económicos de la actividad minera, no le permite realizar inversiones y mejoras significativas en sus títulos; el 40\% afirma que las utilidades apenas alcanzan para hacer pequeñas inversiones, pero que no permiten incrementar la producción; el $20 \%$ está satisfecho con las inversiones que ha podido efectuar y el $10 \%$ asevera que ha hecho medianas inversiones, ha mejorado las condiciones y aumentado la producción del título, abriéndose oportunidades en nuevos mercados. Sin embargo, la falta de organización empresarial incrementa las debilidades de las pequeñas empresas mineras.

Estructura orgánica empresarial: El $60 \%$ de la población no cuenta con una estructura orgánica definida en su empresa, el $20 \%$ no sabe qué es una estructura orgánica y menos la importancia que tiene para el buen funcionamiento de una empresa u organización, el $15 \%$ de los titulares tiene establecida la estructura orgánica en su título, el 5\% de los encuestados no consideran su importancia para el buen desempeño de su título.

Tamaño de la empresa: El estudio muestra que el $70 \%$ de los titulares son microempresarios, ya que poseen entre 1 y 10 trabajadores; el 25\% pertenece a pequeños empresarios que contratan entre 10 y 20 trabajadores, y solo en $5 \%$ pertenecen a medianos empresarios y poseen mayor capacidad de contratación e inversiones.

Producción mensual de carbón: El $60 \%$ de los titulares tiene una producción mensual menor a 500 toneladas, el $20 \%$ de los entrevistados oscila entre 500 y 1000 toneladas de carbón, el 15\% entre 1000 y 2000 toneladas y el $5 \%$ produce más de 2000 toneladas de carbón, siendo este último el más productivo de los titulares. Que el $60 \%$ de los titulares tenga una producción menor a 500 toneladas, significa un bajo nivel de productividad y competitividad de la minería en esta zona del departamento de Boyacá, ya que la demanda de carbón se encuentra insatisfecha y deben 
proveerse de otros mercados y centros de acopio de la región, sin embargo esta situación ocasiona mayores costos, que principalmente se generan en el transporte.

Satisfacción demanda y estrategias competitivas: El estudio muestra que el $95 \%$ de los demandantes en el mercado del carbón, está insatisfecho debido a la baja producción que suministran los titulares mineros, los demandantes afirman que deben proveerse de varias empresas mineras; el 5\% considera que provee carbón suficiente a sus compradores, el $90 \%$ de los titulares considera que carecen de apoyo gubernamental en aspectos técnicos, empresariales, legales, ambientales, que les permita fortalecer sus empresas mineras, el $10 \%$ de los entrevistados, considera que se sienten fortalecidos en estos aspectos, debido a que se han capacitado de manera particular, haciendo contrataciones con profesionales de las distintas áreas.

\subsection{Fortalezas y debilidades}

Fortalezas: Los titulares mineros del distrito norte de Boyacá, cuentan con una importante fortaleza y es que, en su mayoría, poseen reservas de carbón para ser explotadas en los próximos diez años.

Los empresarios mineros entrevistados, cumplen legalmente, ya que tienen aprobado ante la entidad competente un PTO (plan de trabajo y obras) y PMA (plan de manejo ambiental), lo cual les permite operar en condiciones normales y con los requerimientos legales. No obstante, hay que señalar que esta situación, de acuerdo con los datos aportados en la parte inicial de esta investigación, no es la usual en la pequeña minería, toda vez que en este sector hay un gran problema de ilegalidad.

Una importante fortaleza es la experiencia y conocimiento que tienen los empresarios en el campo de la exploración y explotación minera.

Los empresarios mineros manifiestan interés en capacitaciones y actividades que contribuyan al mejoramiento de la productividad y competitividad, en aspectos empresariales, seguridad minera, salvamento minero, legalidad, parte ambiental, geológica y minera.

Los entrevistados, en su mayoría, reconocen que su producción no aporta significativamente a las cifras nacionales de producción y de exportaciones, pero sí saben que su producción y su presencia en la región genera impacto social representado en generación de empleo, desarrollo regional y local.

En esta zona minera se encuentra una importante fortaleza y es que existen empresas demandantes de los diferentes tipos de carbón, que deben abastecerse de otros municipios aledaños, debido a que no encuentran un productor que satisfaga sus necesidades. En otras palabras, aquí se encuentra una importante oportunidad de mercado unificando producciones.

Debilidades: Dentro de las debilidades encontradas y manifestadas por los entrevistados, se encuentra la falta de estructura de costos en cada uno de los títulos, ya que se desconocen costos de producción, ingresos, egresos, rentabilidad, gastos administrativos, financieros, utilidad neta, punto de equilibrio, no se realiza planeación estratégica para inversiones y financiamiento a lo largo del tiempo y de la vida útil de sus proyectos mineros.

En términos generales, los títulos carecen de tecnología, maquinarias, herramientas, equipos, infraestructura adecuados para aumentar la productividad y competitividad en la región. Los entrevistados argumentan que las principales causas se encuentran en las fuentes de financiación, ya que la banca nacional requiere de importantes garantías y respaldo al momento de otorgar créditos.

Dentro del estudio, los titulares manifestaron que los trabajadores NO son constantes en su trabajo, abandonan sus puestos y esto les trae problemas 
como gastos, representados en afiliaciones a seguridad social, dotaciones, entrenamiento, entre otros; pero tampoco se pudo ver que los propietarios tuvieran planes y programas enfocados en el desarrollo del talento humano.

En las carteleras puestas en los casinos de los trabajadores, no se encuentran procesos documentados como: estructura orgánica, manual de funciones, manual de procesos, reglamento interno de trabajo, entre otros.

No existe estructura orgánica definida, que les permita delegar funciones, establecer objetivos, misión, visión, metas, delegar responsabilidades, no existen documentos para evaluación del desempeño y capacitación del personal.

Para los titulares mineros existe resistencia al tema de la asociatividad por ausencia de confianza entre los diferentes agentes que intervienen.

No se conoce información sobre el comportamiento del negocio del carbón a nivel nacional e internacional de los mineros del distrito norte de Boyacá.

Los titulares mineros carecen de estrategias unificadas, que les permitan mejorar y ampliar los canales de comercialización, a fin de visualizar nuevos mercados a medio y largo plazo.

\subsection{Estrategias de mejoramiento}

Las estrategias propuestas a continuación se basan en las políticas de mejoramiento trazadas por el Gobierno nacional, las cuales están orientadas principalmente a la atracción de inversión extranjera, aprovechando el potencial de reservas de carbón que tiene el departamento de Boyacá, que asciende a 153.950 millones de toneladas (Sistema de Información Minero Colombiano [SIMCO], 2012). También se busca fortalecer los mercados internacionales, como lo hicieron los países asiáticos y países desarrollados, aumentando así, la competitividad y productividad de la minería. El Gobierno nacional ha propuesto en sus políticas mineras, la formalización de la minería de pequeña escala en cuatro importantes pilares: asociatividad, financiación, asistencia técnica y capacitación, enfocando sus esfuerzos a consolidar empresas mineras sostenibles técnica, económica y ambientalmente, a fin de que puedan permanecer a lo largo del tiempo.

Estrategia empresarial: Se dirige a orientar el buen funcionamiento de las empresas mineras, a través de: facilidades de acceso a capital de trabajo, acceso a tecnología adecuada, conocimiento del negocio minero y capacitación del talento humano, conocimiento e investigación del mercado de los minerales, asociatividad empresarial, consolidación empresarial y organizacional (Duque, Preciado \& Sierra, 2005).

El convencimiento de quienes creen que basta saber leer, escribir, sumar y restar para convertirse en gerente de una empresa minera, les impide comprender que la falta de preparación y capacitación no les permite crecer en términos empresariales con solidez y permanencia. En este sentido, la decisión 1994/308 del Consejo Económico y Social de la ONU, el Comité de Recursos Naturales de ese organismo en su tercer período de sesión, recomendó prestar asistencia técnica a la minería artesanal, al igual que asistencia en esferas como actividades optativas que generen ingresos, la educación, la salud y el apoyo de la mujer, en tanto que la minería artesanal constituye un soporte fundamental de sobrevivencia, que puede ser propicio para incrementar actividades de desarrollo socioeconómico integral y multisectorial.

Lo anterior a partir de que la minería en pequeña escala debe considerarse desde el punto de vista más amplio del desarrollo socioeconómico y la erradicación de la pobreza para un gran número de personas que participan en la minería artesanal en todo el mundo, las actividades de minería constituyen una red de seguridad ya que 
proporcionan ingresos durante épocas económicas difíciles. Dado que la mayoría de esas actividades se realizan en zonas rurales, la minería artesanal es un arma eficaz contra la pobreza rural y la migración de las zonas rurales a las urbanas $y$, como tal, debe recibir apoyo. Cuando un gobierno toma medidas para crear un entorno más propicio para los mineros artesanales, está aumentando también el acceso de la población a una red de seguridad de los ingresos y generando capacidad para liberarse de la pobreza, la asistencia a ese sector puede servir también de mecanismo importante para prestar la ayuda social que tanto necesitan la población y las zonas involucradas. (ONU, 1994)

Estrategia financiera: Establecer la estructura de costos: capital de trabajo, activo, pasivo, patrimonio, indicadores contables, créditos, tasas de interés.

Se deben establecer proyectos que alcancen etapas de prefactibilidad que permitan entrar a procesos serios de negociación, se requiere invertir capitales importantes en exploración minera. Estas inversiones tienen como características principales que son de muy alto riesgo y altamente intensivas en capital, para lo cual se trabajará en el análisis de la viabilidad de conformar un Fondo Rotatorio de Capital de Riesgo para Industria Minera, con el que se esperaría suplir esa necesidad de la minería a pequeña y mediana escala que no cuenta con la capacidad financiera para gestionar estos recursos (Duque et al., 2005).

Los proyectos que ya han sido estudiados y han pasado a etapa de factibilidad, deben configurar un plan de inversiones para el montaje de las operaciones. En esta etapa se trabajará en la conformación de mecanismos de financiación a través de la banca, o en facilitar el acceso a mercados de capitales consolidados, donde el Estado servirá de facilitador entregando toda la información necesaria a los empresarios mineros, bolsa de valores y corredores de bolsa en la captación de capitales para estos proyectos mineros. Estos proyectos logran un mayor impacto cuando se realizan en términos asociativos, es decir, son más consolidados (Duque et al., 2005).

Estrategia de mercado: Los mineros no tienen buen conocimiento de mercados regionales, nacionales e internacionales, venden sus productos a intermediarios locales y sus márgenes de utilidad son bajos. En muchas ocasiones su producción se vende al dueño del transporte o a centros de acopio de la región y no se genera valor agregado en el producto desde las minas. Los pequeños mineros afirman que los intermediarios son los responsables de que el carbón no sea un negocio rentable para ellos. "No es justo que los principales proveedores de Gensa, empresa que maneja las termoeléctricas de Paipa, sean intermediarios, lo que obliga a que nosotros tengamos que venderles el carbón al precio que ellos digan", (Portafolio, 2011).

Estrategia de asociatividad: Teniendo en cuenta lo señalado en el artículo 224 y en el Capítulo XXIV de la Ley 685 de 2001, Código de Minas, la carencia o debilidad de las estructuras empresariales podría ser superada mediante formas asociativas que permitan la adopción de esquemas empresariales financiera y económicamente viables (Duque et al., 2005). Es una iniciativa empresarial que integra las comunidades de bajos ingresos como protagonistas en la cadena valor, como consumidores, proveedores o distribuidores.

Las difíciles circunstancias en las cuales se desenvuelve la minería de pequeña escala, siempre ha motivado a quienes la ejercen a pensar en asociarse. Sin embargo, una aproximación crítica de los actuales modelos cooperativos sugiere que han resultado incapaces para responder al reto del desempleo y de fortalecer nuevos vínculos de producción. Estos modelos cooperativos no han podido despegar bien en el campo minero, por cuanto la esencia misma de la actividad, las dificultades en el mercadeo de los 
minerales que han producido por los socios mineros han impedido el desarrollo de esta iniciativa.

En el caso minero puede y debe impulsarse variantes de las opciones minero-cooperativas, como por ejemplo la posibilidad de atender bajo este modelo las necesidades locales tales como servicios de reparación y mantenimiento de máquinas, equipos y herramientas, limpieza y mantenimiento de caminos y sistemas de acueducto, recolección y reciclaje de desechos. No se puede dejar de lado la posibilidad de desarrollar labores de cooperación que generan trabajo atendiendo labores de carácter social en especial para las parejas de los desempleados tales como cuidado de niños, cuidado de personas de la tercera edad y servicios en general Munkner, (1998) citado por (Chaparro, 2000).

Estrategias técnicas y operativas: Aspectos técnicos operacionales: cálculo de reservas que permitan determinar el potencial minero disponible en cada uno de los títulos, evaluar y controlar la estabilidad de taludes, (compra, almacenamiento, manejo, control y uso de explosivos e insumos para los procesos de explotación y beneficio), evaluar la disponibilidad de maquinaria, equipo y tecnología adecuada para el buen desempeño de la actividad minera.

Evaluación preventiva y correctiva de operaciones técnicas como: arranque, cargue, transporte, sostenimiento, ventilación, desagüe e iluminación.

Evaluación y control de los sistemas y métodos de explotación empleados (bajo tierra, cielo abierto).

Mantener y garantizar las condiciones de seguridad e higiene, seguridad industrial (suministro y uso de elementos de protección personal), establecer programas que fomenten la cultura de la prevención de accidentes, así mismo los respectivos registros de índices de accidentalidad, mencionando las causas más frecuentes, y las acciones de prevención implementadas (en caso de existir algún tipo de accidente) y plantear las recomendaciones a que haya lugar para su mejoramiento. También se debe capacitar de forma periódica al personal vinculado con la mina, en temas de uso y manejo de equipos para el control de gases y la forma de llevar los registros de las mediciones.

Pese a que la producción de carbón en Boyacá se ha disparado en los últimos cinco años, todavía en el departamento hay un gran número de explotaciones mineras artesanales. "En la región de Samacá y Ráquira se ha venido mejorando en mecanización de minas, pero aún hay minería artesanal en las provincias de Sugamuxi y Valderrama", manifestó el gerente de Cooprocarbón de Samacá, Carlos Sierra. Agregó que la falta de tecnificación reduce la producción de carbón y puede aumentar la inseguridad dentro de las minas (El Tiempo, 2012). Los productores de carbón están de acuerdo en que la tecnificación de sus minas los haría más competitivos, pero aseguran que la inestabilidad de los precios del producto no les permite hacer las inversiones que ellos quisieran. La falta de tecnología también repercute en la accidentalidad minera, pues cuando no se utilizan los equipos adecuados se pone en riesgo al trabajador.

"Muchas minas aún mantienen adentro motores de combustión interna para extracción de agua y estos generan monóxido de carbono", dijo el ingeniero Sigifredo Preciado, gerente de Polsermin, empresa de seguridad, salvamento y mecanización de minas. Indicó que a la falta de tecnificación se suma la no capacitación de muchos de los trabajadores de minas. "Creo que la falencia más grande que tiene la minería es la falta de capacitación básica para el minero. La capacitación lo habilitaría para que maneje los riesgos, maneje la parte ambiental y maneje el tema operativo de la mina de forma rentable y segura", (El Tiempo, 2012). Por eso los retos de la minería del carbón apuntan hacia una actividad 
con mayor tecnificación, que reduzca la accidentalidad y que sea amigable con el medio ambiente.

Estrategias de tipo ambiental: Desde el punto de vista ambiental, la industria minera debe cumplir con una serie de requisitos y parámetros que conlleven a la preservación, mantenimiento y protección del medio ambiente. De no hacerlo, se pueden presentar situaciones como: en el último año han muerto más de 150.000 truchas en piscifactorías de los municipios de Socotá y Tasco. Los piscicultores culpan de la mortandad de peces a las explotaciones de carbón. La más reciente mortandad acabó con 75.000 peces. Adicionalmente, Boyacá no es ajena a los problemas del otorgamiento de títulos mineros en zonas de reserva natural, especialmente páramos. Este año se han cerrado en Boyacá más de 300 bocaminas por no cumplir con normas vigentes. Gran parte de las minas están en zona de montaña (Portafolio, 2011).

Los títulos mineros deben cumplir con el Plan de Manejo Ambiental, PMA, y este debe estar aprobado por la entidad correspondiente; en el caso de Colombia por las corporaciones de manejo ambiental. Los PMA deben incluir programas de mitigación de los impactos ambientales como:

La disposición de estériles (existencia y características de botaderos). Disponer de programas de recuperación, corrección como plantaciones de especies nativas.

Mantenimiento, manejo y control de vertimientos de aguas.

Tratamiento y disposición de residuos químicos, orgánicos, sanitarios, entre otros presentes en las minas.

Manejo y disposición de aceites quemados (estos deben ser entregados a un agente externo).
Manejo de basuras (se debe fomentar la cultura de reciclaje y selección en la fuente).

\section{Conclusiones}

La pequeña minería ubicada en el distrito minero del norte de Boyacá carece de capacidades técnicas y financieras y de recursos humanos, para fortalecer e incrementar la productividad y competitividad de la minería de esta zona del país. La actividad minera de este distrito muestra que faltó planeación desde el inicio, ya que no se realizaron proyecciones a corto ni medio plazo y con ello hubo problemas en la ejecución de los Planes de Trabajo de Obras y de Manejo Ambiental, PTO y PMA, respectivamente.

En términos generales, los títulos carecen de tecnología, maquinarias, herramientas, equipos e infraestructura adecuados. Las principales causas se encuentran en las fuentes de financiación, ya que la banca nacional requiere de importantes garantías y respaldo al momento de otorgar créditos.

El sector empresarial debe demostrar que la minería es una palanca del desarrollo no solo con adecuadas prácticas laborales, de seguridad industrial y ambiental, sino con la construcción de relaciones de confianza con las comunidades e invertir en la diversificación de la producción local generando nuevas capacidades productivas.

Por último, se destaca que en el distrito minero del norte de Boyacá, existen reservas de mineral suficientes para ser explotadas en las próximas dos décadas, sin embargo se requieren labores mineras mecanizadas con infraestructura, maquinaria, herramientas y tecnologías adecuadas, que permitan la extracción de material desde el punto de vista sostenible en los aspectos técnico, ambiental, jurídico, económico, empresarial y social. 


\section{Referencias}

Agencia Nacional de Minería ANM. (2013, 14 de agosto). Producción de carbón en pequeña y mediana minería crece $2 \%$. Recuperado de: https://www.anm.gov.co/?q=Produccion_carbon _pequenaymediana_mineria_crece_2porciento

Ardila. M. (2010). Minería de hecho en Colombia. Bogotá:Imprenta Nacional.

Banco Mundial. (2002). De los recursos naturales a la economía del conocimiento. Washingt D.C.:WB.

Benavides, J. \& Rosso, J. (2012). Propuesta de estructura para la minería de carbón en Boyacá. Congreso Nacional de Minería, pp. 1-17.

Chaparro, E. (2000). La llamada pequeña minería: un renovado enfoque empresarial. Publicación de la Naciones Unidas CEPAL.

Commission on Industrial Competitiveness. (1985). Report. Washington. Retrieved from: www.finance.senate.gov/library

Departamento Nacional de Planeación DNP. (2010). Plan Nacional de Desarrollo 2010-2014. III Crecimiento sostenible y competitividad. Bogotá: DNP. Recuperado de https://www.dnp.ov.co/Link Click.aspx?fileticket=6yjofaugVUQ\%3D\&tabid=1 238

Duque, B., Preciado, L. \& Sierra, J. (2005). Política de mejoramiento de la productividad y la competitividad del sector minero. Recuperado de http://www.minminas.gov.co/minminas/downlo ads/UserFiles/File/INGLES/PoliticaMejoramiento. pdf

Herrera, J. \& Gamba, G. (2006). Competitividad del sector minero. Escenarios y estrategias minería y energía. Unidad de Planeación Minero Energética № 10. Bogotá. Recuperado de: http://www.upme. gov.co/Docs/Escenarios002.pdf
Krugman, P. (1992). The age of diminished expectations. Revista Banco de la República, Bogotá.

Martínez O, A \& Aguilar, T. (2012). Impacto Socioeconómico de la minería en Colombia. Recuperado de http://www.fedesarrollo. org.co/wp-content/uploads/2011/08/Impactosocioecon\%C3\%B3mico-de-la-miner\%C3\%ADaen-Colombia Informe_Impacto_de_la_miner\%C 3\%Ada_Final-26-abril.pdf

Mineralco S.A. (1999). Informe de gestión 19941998. Bogotá:s.n.

Ministerio de Minas y Energía. (2002). Plan Nacional de Desarrollo Minero 2002-2006. Recuperado de: http://www.minminas.gov.co/ minminas/downloads/UserFiles/File/Minas/plan. pdf

Ministerio de Minas y Energía. (2003). Glosario técnico minero. Recuperado de: http://www.min minas.gov.co/minminas/downloads/UserFiles/Fil e/Minas/Glosario\%202.pdf

Ministerio de Minas y Energía. (2011). Promoción y fortalecimiento de la asociatividad en los distritos mineros. Recuperado de: http://www.minminas. gov.co/minminas/downloads/UserFiles/File/Mina s\%20Anllela/Boletines/Espanolb16web.html

Mintzberg, H. (1997). El proceso estratégico: conceptos, contextos y casos. S.I.: Prentice Hall Hispanoamericana.

Moncayo, E. (2003). Geografía económica de la Comunidad Andina: Las regiones activas en el mercado comunitario. Lima:s.n.

Organización de las Naciones Unidas [ONU]. (1994). Decisión 1994/308 del Consejo Económico y Social. NY:ONU. 
Organización de las Naciones Unidas. (1996). Informe del Comité de Recursos Naturales. Tercer período de sesiones, Acontecimientos en la minería en pequeña escala. Informe E/C.7/1.996/9.

Peace Brigades International PBI. (2011). Minería en Colombia ¿A qué precio? Boletín Informativo (18). Recuperado de: http://www.peacebrigades. Org /fileadmin/ user_ files/projec. ts/colombia/ files/colom PBla/111122_boletin_final_web.pdf

Portafolio. (2011, 2 de abril). Carbón, una industria que no despega en la zona de Boyacá. Recuperado dehttp://www.portafolio.co/economia/carbonuna-industria-que-no-despega-la-zona-boyaca

Porter, M. (1998). Clusters and the New Economic of Competition. Harvard Business Review.

Porter, M. (1999). La ventaja competitiva de las naciones. Madrid:Deusto.

Porter, M. (2000). Estrategia competitiva. Técnicas para el análisis de los sectores industriales y de competencia. México: CECSA.

Ramos, J. (1998). Una estrategia de desarrollo a partir de los complejos productivos (clusters) en torno a los recursos naturales. Revista CEPAL, (66).

Redacción Boyacá 7 Días. (2012, 15 de marzo). Los retos para esta industria. El Tiempo.com. Recuperado de: http://www.eltiempo.com/colom b i a / b o y a c a / A R T I C U L O - W E B NEW_NOTA_INTERIOR-11362801.html

Sistema de Información Minero Colombiano SIMCO. (2012). Boletín Colombia minera. Recuperado de: http://www.simco.gov.co/ BoletinDesdelaColombiaMinera/Noticias_15/tabi d/412/Default.aspx.

Unidad de Planeación Minero Energética (1997). Plan Nacional de Desarrollo Minero de Colombia. Bogotá:Preprensa.

Unidad de Planeación Minero Energética [UPME]. (2002). Plan Nacional de Desarrollo Minero PNDM. Bogotá: Dígitos y Diseños. Recuperado de: http://www.simco.gov.co/simco/Documentos delnteres/Plan NacionaldeDesarrolloMinero/ tabid/94/Default.aspx

Unidad de Planeación Minero Energética. (2005). Distritos mineros. Recuperado de http://www. upme.gov.co/Docs/Distritos_Mineros.pdf

Unidad de Planeación Minero Energética. (2006). Plan Nacional de Desarrollo Minero Visón al año 2019. Bogotá: Preprensa. Recuperado de: http://w ww.upme.gov.co/Docs/PNDM_2019_Final.pdf

US Geological Survey. (2011). Mineral Commodities Summaries 2011. Science for a changing world. Virginia, US:s.n. 